\title{
Influence of Chinese Enterprises on the Agricultural Investment Mode and Performance in Laos under Institutional Distance
}

\author{
Xuekun Li, Yuqin Zhang*, Jing Jin \\ School of Economics and Management, Yunnan \\ Agricultural University \\ Kunming, Yunan, China, 650201
}

\author{
Yu Zhang \\ Yunnan Plateau Characteristic Agricultural Industry \\ Research Institute \\ Kunming, Yunan, China, 650201
}

\begin{abstract}
In the 21st century of economic globalization, foreign direct investment has gradually become the main mode for international capital flow. As one of the countries that directly invested Laos earlier, China has become an indispensable partner of trade investment activities in Laos. As per the traditional concept, Sino-Laos institutional distance is small, which should has small influence on investment mode and performance, but in practice, the situation is quite the opposite. To study reasons causing inconformity of traditional theories and practice, this paper adopted field visit and designed questionnaires to investigate Chinese agricultural enterprises in Laos, and adopted more than two logistic regression model and OLS to build conceptual model and hypothesis influencing on agricultural investment and operation mode and performance of Chinese enterprises in Laos based on the recognition of institutional distance, and verified the influence of institutional distance on agricultural investment mode and performance. As the result indicates: Under the same institutional distance, the difference in the corporate recognition of system will influence the investment mode and operational performance of the enterprise. Under the official institutional distance, the institutional distance of economy and finance can exert an obvious influence, but in the nonofficial institutional distance, factors of cultural and psychological distance are more sensitive. Therefore, in this era when foreign investment is becoming increasingly important, Chinese enterprises should emphasize on the bilateral coordination of system resources, recognize cultural differences, narrow the gap as much as possible, and actively advocate the principle of seeking common points while reserving differences in respect of the institutional distance of the two countries.
\end{abstract}

Keywords-formal institutional distance; nonofficial institutional distance; agricultural investment mode; agricultural investment performance

\section{INTRODUCTION}

In the 21st century, economic globalization has increased the mutual dependence and influence of all countries worldwide, and all countries have enlarged the foreign investment force, and entered a deeper and wider scope of development. Foreign direct investment (FDI) has shown increasingly obvious and unique advantages in international trade, and has gradually become the main mode for international capital flow [1]. As "Belt and Road" strategies are implemented and the cooperation of international productivity is further promoted, foreign direct investment also gradually becomes a new route for our commodities and capitals to go global. It will be of increasing significance to study the foreign direct investment of Chinese enterprises in southeast Asian countries [2].

Due to geological advantages, rich resources, and low production elements, Laos has strong economic complementarity with China, and has become one of the major fronts of China in South Asia and Southeast Asia Interconnection Strategy and Greater Mekong Regional Economic Cooperation. In trade contacts over the years, Laos has gradually become one of the countries directly invested by China [3]. According to the traditional view, due to regional and national reasons, the institutional distance between China and Laos is relatively small [4]. However, in practice, institutional distance of the two countries can exert a big influence on the agricultural investment mode and performance of China in Laos, and this will cause the phenomenon of inconsistence between theories and practice. Further study and analyze the problems and main barriers of Chinese enterprises in the agricultural investment in Laos, to improve the scale, quality and level of agricultural investment in Laos. This paper tries to study such problems, analyze the reasons, and puts forward some suggestions for Chinese agricultural enterprises in foreign agricultural investment. Meanwhile, it has also supplemented the behavior of agricultural foreign investment in theory.

\section{OBJECT AND METHOD}

\section{A. Selection and design of data model}

On the basis of reviewing relevant references about the measurement of current institutional distance, this study selects four dimensions of the institutional distance, including policy, economy and finance, laws and culture [5]. By sending questionnaires to China-funded agricultural enterprises in Laos and combining field interview, it adopts the model to analyze the agricultural investment mode of Chinese enterprises in Laos on the basis of the recognition of different groups about the system environment, and analyze the influence of operational business by combing with the institutional distance. 


\section{B. Design and main content of the questionnaire}

The design of questionnaire mainly involves two parts. In the investigation, 68 questionnaires were sent to Chinese agricultural enterprises in Laos, and 62 questionnaires were recovered. The effective rate of the questionnaire is $91.17 \%$. Part 1 is the basic conditions about Chinese enterprises engaged in agricultural production and operation in Laos, including corporate features, operational scale, time of establishment, investment scale, personnel quantity, operational performance and investment business mode. In the process of performance investigation, in order to avoid enterprises from the reluctance to disclose their profitability, we adopt the average profit of the investigated enterprises in the past five years as the operational performance index. In empirical analysis, institutional distance includes policy, economy, laws and culture as well as psychological elements.

Part 2 is the emphasis of the investigation, and mainly involves opinions of corporate owners about Sino-Laos institutional distance. In order to facilitate respondents to answer questions directly, the questionnaire is aimed to rate specific problems between China and Laos, and the rating scope is from 0 to 12 . Finally, relevant calculations will be implemented as per scores of the two countries.

\section{Method to verify theoretical assumption}

Binomial and multiple logistic regression model are adopted to analyze the selection of the investment business model. When studying the influence of institutional distance perception on the selection of commercial investment mode, since investment business model is a qualitative variable, the quantity of quantification is unrelated to the scale, but for category [6], when using such variable as the dependent variable in logistic regression model. In regression analysis, corporate business performance is used as the continuous dependent variable, and the least square method (OLS) is adopted to execute general multiple linear regression.

\section{Settings of model variables and measurement of institutional distance}

Dependent variables in the paper involve two aspects, i.e., the corporate investment efficiency and the corporate investment mode. It is generally quite difficult and even impossible to get the financial statement index of Chinese agricultural investment enterprises in Laos, so we regard the net profit of enterprise as the investment income index of the enterprise; However, we have found by investigation that, when it comes to the corporate investment mode, it generally includes three types, i.e., independent investment, joint stock partnership, and agricultural S\&T demonstration parks. Generally, we can use 0 to represent independent investment, 1 to represent joint stock partnership and 2 to represent agricultural S\&T demonstration parks in quantification. According to the investigation, we have found that Chinese agricultural investment enterprises in Laos only involve two types, solely-invested and joint stock partnership.

With respect to the selection of variables, institutional distance involved in the paper is an independent variable, i.e., the recognition of China on the institutional distance from four dimensions, including the policies, economy and finance, laws and culture of agricultural investment enterprises in Laos. These data can be calculated by the investigation data in the investigation table items. After referring to the study on other related literatures, and considering other variables may influence the corporate performance or investment mode, in respect of control variables involved in the regression analysis, this paper regards the establishment year of the enterprise, the scale of the enterprise, and the corporate organization property as the major control variables.

\section{RESULT AND ANALYSIS}

\section{A. Reliability analysis}

(1)Cronbach's Alpha coefficient analysis result under the table items of institutional distance of policy. The institutional distance of policy mentioned in the questionnaire generally refers to political risks, including 5 types, i.e., the efficiency of government affairs, the transparency of the government for corporate policies, the possibilities of fast changes in government policies, the influence of government policies on corporate investment and management activities as well as the corruption degree of the government. The calculation result for the table item of institutional distance of policy is 0.712 , which can indicate that this is a relatively reliable scope, and can meet the analysis requirements.

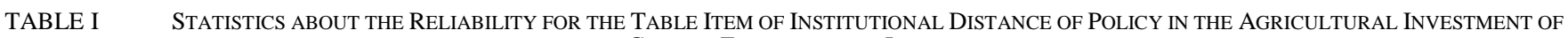
CHINESE ENTERPRISES IN LAOS

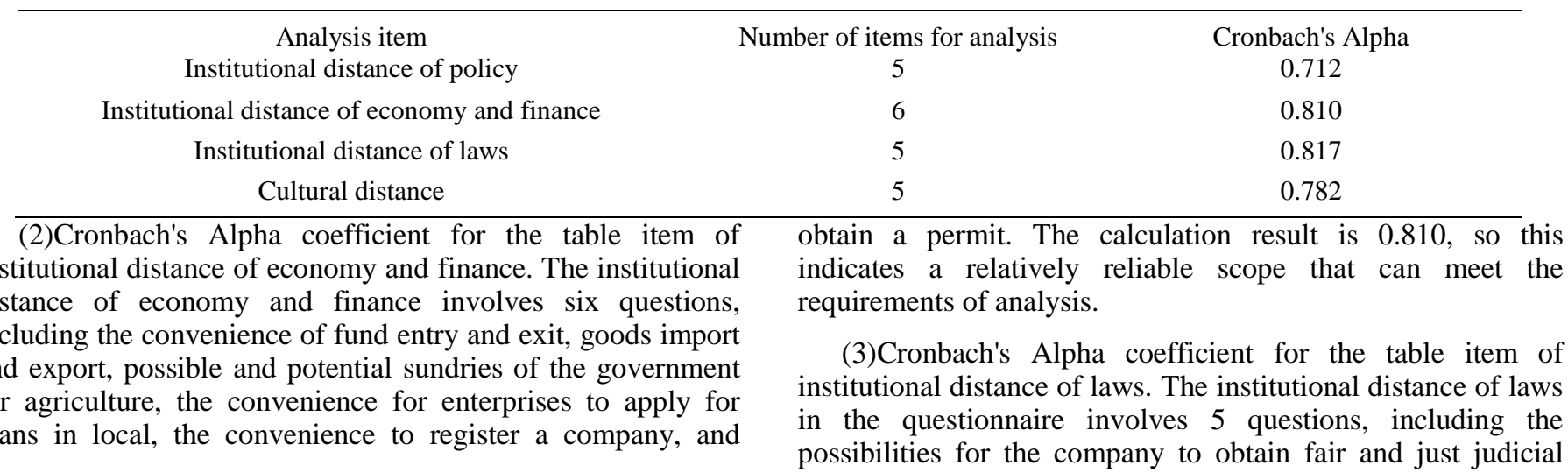


decisions, the degree of effectiveness for the company in executing laws and regulations, the degree for enterprises to solve disputes by court lawsuit procedures. Laws and police force can effectively protect the property safety and personal safety of the company, and effectively ensure the degree of performance for business contracts. The calculation result is 0.817 , and can basically meet the reliability requirements for analysis.

(4)Cronbach's Alpha coefficient for the table item of cultural distance. The cultural distance of the questionnaire includes five questions, i.e., whether they can adapt to the local social conventions, the enthusiasm for the staff to participate in corporate activities, the degree of implication for the opinions expressed by the staff, the degree of emphasis for the staff on corporate management practice as well as the subordinate authorization. The result is 0.782 , so the reliability can meet the analysis requirements.

\section{B. Validity analysis}

(1)Analysis on the effectiveness for the table item of the institutional distance of policy considering the agricultural investment of Chinese enterprises in Laos. Regard KMO as 0.619 , and $\mathrm{p}$ value for Bartlett sphericity inspection shall be less than 0.05 of significance level (Table 2). Analysis shows that, factor analysis is applicable for the table item of Sino-Laos institutional distance of policy.

TABLE II KMO MEASUREMENT AND BARTLET INSPECTION ON THE TABLE ITEM OF INSTITUTIONAL DISTANCE CONSIDERING THE AGRICULTURAL INVESTMENT OF CHINESE ENTERPRISES IN LAOS

\begin{tabular}{llcccc}
\hline Analysis item & & Political system & $\begin{array}{c}\text { economy and finance } \\
\text { system }\end{array}$ & Legal system & Cultural system \\
\hline KMO measurement & & 0.619 & 0.759 & 0.743 & 0.802 \\
Bartlett inspection & $\begin{array}{l}\text { Approximate } \\
\text { ly X }\end{array}$ & 89.711 & 193.121 & 112.543 & 96.080 \\
& $\begin{array}{l}\text { Freedom } \\
\text { degree }\end{array}$ & 10 & 15 & 10 & 10 \\
& Significance & 0 & 0 & 0 & 0 \\
\hline
\end{tabular}

According to the gravel figure, the accumulative contribution rate of three main components extracted by factor analysis is close to $90 \%$. This indicates that three main components can explain most changes to the institutional distance of policy between China and Laos.

TABLE III EXPLANATORY TOTAL VARIANCE AND ROTATING COMPONENT LOAD FOR THE TABLE ITEM OF INSTITUTIONAL DisTANCE OF POLICY CONSIDERING THE AGRICULTURAL INVESTMENT OF CHINESE ENTERPRISES IN LAOS

\begin{tabular}{|c|c|c|c|c|c|c|}
\hline \multirow[t]{2}{*}{ Table item of institutional distance of policy } & \multirow{2}{*}{\multicolumn{3}{|c|}{$\begin{array}{c}\text { Initial characteristic value/extraction } \\
\text { square and loading }\end{array}$}} & \multicolumn{3}{|c|}{ Re-scaled component } \\
\hline & & & & 1 & 2 & 3 \\
\hline Government affair efficiency & 79.303 & 21.798 & 80.986 & 0.645 & 0.270 & 0.560 \\
\hline $\begin{array}{l}\text { Transparency of the government for corporate } \\
\text { policies }\end{array}$ & 32.742 & 9.000 & 89.985 & 0.161 & 0.166 & 0.951 \\
\hline Possibilities for fast changes to government policies & 26.097 & 7.173 & 97.158 & 0.390 & 0.659 & 0.117 \\
\hline $\begin{array}{l}\text { Influence of government policies on corporate } \\
\text { investment and management activities }\end{array}$ & 10.338 & 2.842 & 100.000 & $0-.116$ & 0.917 & 0.177 \\
\hline Government corruption degree & 215.336 & 59.188 & 59.188 & 0.976 & -0.003 & 0.136 \\
\hline
\end{tabular}

As can be seen from the main component load, main component 1 mainly extracts government affair efficiency; main component 2 mainly extracts the transparency of the government for corporate policies, while main component 3 mainly extracts the possibilities for fast changes to government policies. Since sub-load is as expected, this indicates that Chinese enterprises are satisfied about the structural efficiency of the component table for institutional distance of policy considering the agricultural investment in Laos. (Table 3)
2. Analysis on the effectiveness for the table item of the institutional distance of economy and finance considering the agricultural investment of Chinese enterprises in Laos. Regard $\mathrm{KMO}$ as 0.759 , and the result of variable correlation is checked by $\mathrm{KMO}$ and Marlette inspection and $\mathrm{p}$ value for Bartlett sphericity inspection shall be less than 0.05 of significance level. 
TABLE IV EXPLANATORY TOTAL VARIANCE AND ROTATING COMPONENT LOAD FOR THE TABLE ITEM OF INSTITUTIONAL DISTANCE OF ECONOMY AND FINANCE CONSIDERING THE AGRICULTURAL INVESTMENT OF CHINESE ENTERPRISES IN LAOS

\begin{tabular}{|c|c|c|c|c|c|c|}
\hline \multirow{2}{*}{$\begin{array}{l}\text { Table item of institutional distance of economy } \\
\text { and finance }\end{array}$} & \multicolumn{3}{|c|}{ Initial characteristic value } & \multicolumn{3}{|c|}{ Component } \\
\hline & Total & Variance & $\begin{array}{l}\text { Cumulative } \\
\text { ratio }(\%)\end{array}$ & 1 & 2 & 3 \\
\hline The convenience of fund entry and exit & 0.780 & 12.996 & 88.002 & 0.441 & 0.784 & -0.062 \\
\hline The convenience of goods import and export & 0.338 & 5.632 & 93.633 & 0.775 & 0.462 & -0.232 \\
\hline Possible and potential sundries of the government & 3.409 & 56.819 & 56.819 & 0.054 & 0.087 & 0.977 \\
\hline for agriculture & & & & & & \\
\hline The convenience for enterprises to apply for loans & 1.091 & 18.186 & 75.006 & 0.172 & 0.897 & 0.196 \\
\hline in local & & & & & & \\
\hline The convenience to register a company & 0.232 & 3.867 & 97.500 & 0.905 & 0.263 & 0.046 \\
\hline The convenience for enterprises to obtain a permit & 0.150 & 2.500 & 100.000 & 0.896 & 0.169 & 0.197 \\
\hline
\end{tabular}

As can be seen from the main component load, main component 1 mainly extracts the convenience of fund entry and exit, goods import and export, possible and potential sundries of the government for agriculture; Main component 2 mainly extracts the convenience for enterprises to apply for loans in local and register a company; Main component 3 mainly extracts the convenience for enterprises to obtain a permit. Therefore, factor load is as expected. This indicates that Chinese enterprises are satisfied about the structural efficiency of the component table for institutional distance of economy and finance considering the agricultural investment in Laos. (Table 4)

3. Analysis on the effectiveness for the table item of the institutional distance of laws considering the agricultural investment of Chinese enterprises in Laos. The result of variable correlation is checked by KMO and Marlette inspection. Regard KMO as 0.763 and $\mathrm{p}$ value for Bartlett sphericity inspection shall be less than 0.05 of significance level.

TABLE V EXPLANATORY TOTAL VARIANCE AND ROTATING COMPONENT LOAD FOR THE TABLE ITEM OF INSTITUTIONAL DISTANCE OF LAWS CONSIDERING THE AGRICULTURAL INVESTMENT OF CHINESE ENTERPRISES IN LAOS

\begin{tabular}{|c|c|c|c|c|c|c|}
\hline \multirow{2}{*}{ Table item of institutional distance of laws } & \multicolumn{3}{|c|}{ Initial characteristic value } & \multicolumn{3}{|c|}{ Component } \\
\hline & Total & Variance $(\%)$ & $\begin{array}{l}\text { Cumulative } \\
\text { ratio }(\%)\end{array}$ & 1 & 2 & 3 \\
\hline The possibilities for the company to obtain fair and just judicial decisions & 0.780 & 12.996 & 88.002 & 0.129 & 0.893 & 0.313 \\
\hline The degree of effectiveness for the company in executing laws and regulations & 3.409 & 56.819 & 56.819 & 0.834 & 0.417 & 0.027 \\
\hline The degree for enterprises to solve disputes by court lawsuit procedures & 1.091 & 18.186 & 75.006 & 0.178 & 0.300 & 0.920 \\
\hline $\begin{array}{l}\text { Laws and police force can effectively protect the property safety and personal } \\
\text { safety of the company }\end{array}$ & 0.338 & 5.632 & 93.633 & 0.904 & -0.054 & 0.216 \\
\hline Effectively ensure the degree of performance for business contracts. & 0.232 & 3.867 & 97.500 & 0.592 & 0.462 & 0.396 \\
\hline
\end{tabular}

Effectively ensure the degree of performance for business contracts.

As can be seen from the main component load, main component 1 mainly extracts the possibilities for the company to obtain fair and just judicial decisions, the degree of effectiveness for the company in executing laws and regulations, the degree for enterprises to solve disputes by court lawsuit procedures. Main component 2 mainly extracts laws and police force, which can effectively protect the property safety and personal safety of the company; Main component 3 mainly extracts the effective assurance about the degree of performance for business contracts. This indicates that factor load is as expected, and according to the analysis,
Chinese enterprises are satisfied about the structural efficiency of the component table for institutional distance of laws considering the agricultural investment in Laos.

4. Effectiveness measurement for the table item of cultural distance considering the agricultural investment of Chinese enterprises in Laos. KMO and Marlette inspection are adopted to check the correlation of variables. Regard KMO as 0.802 and p value for Bartlett sphericity inspection shall be less than 0.05 of significance level. 
TABLE VI EXPLANATORY TOTAL VARIANCE AND ROTATING COMPONENT LOAD FOR THE TABLE ITEM OF CULTURE DISTANCE CONSIDERING THE AGRICULTURAL INVESTMENT OF CHINESE ENTERPRISES IN LAOS

\begin{tabular}{|c|c|c|c|c|c|c|}
\hline \multirow{3}{*}{ Table item of cultural distance } & \multicolumn{4}{|c|}{$\begin{array}{c}\text { Initial characteristic value/extraction square and } \\
\text { loading }\end{array}$} & \multicolumn{2}{|c|}{ Component } \\
\hline & \multirow[b]{2}{*}{ Total } & \multicolumn{3}{|c|}{ Cumulative ratio } & \multirow[b]{2}{*}{2} & \multirow[b]{2}{*}{3} \\
\hline & & Variance $(\%)$ & & 1 & & \\
\hline $\begin{array}{l}\text { Whether enterprises can adapt to the local social } \\
\text { conventions }\end{array}$ & 0.497 & 9.933 & 94.338 & 0.774 & 0.274 & 0.351 \\
\hline $\begin{array}{l}\text { The enthusiasm for the staff to participate in corporate } \\
\text { activities }\end{array}$ & 0.706 & 14.123 & 71.109 & 0.236 & 0.143 & 0.955 \\
\hline $\begin{array}{l}\text { The degree of implication for the opinions expressed by } \\
\text { the staff }\end{array}$ & 0.665 & 13.297 & 84.405 & 0.202 & 0.940 & 0.145 \\
\hline $\begin{array}{l}\text { The degree of emphasis for the staff on corporate } \\
\text { management practice }\end{array}$ & 2.849 & 56.986 & 56.986 & 0.865 & 0.036 & 0.152 \\
\hline Subordinate authorization & 0.283 & 5.662 & 100.000 & 0.724 & 0.423 & 0.114 \\
\hline \multicolumn{2}{|c|}{$\begin{array}{l}\text { As can be seen from the main component load, main } \\
\text { component } 1 \text { mainly extracts whether enterprises can adapt to } \\
\text { social habits in local, the enthusiasm for the staff to participate } \\
\text { in corporate activities and the subordinate authorization; Main } \\
\text { component } 2 \text { mainly extracts the degree of emphasis for the } \\
\text { staff on the corporate management practice; Main component } 3 \\
\text { mainly extracts the degree of implication for the opinions } \\
\text { expressed by the staff. Therefore, factor load is as expected. } \\
\text { This indicates that Chinese enterprises are satisfied about the } \\
\text { structural efficiency of the component table for institutional } \\
\text { distance of culture considering the agricultural investment in } \\
\text { Laos. }\end{array}$} & \multicolumn{5}{|c|}{$\begin{array}{l}\text { 1. Assumption inspection of institutional distance from four } \\
\text { dimensions. Regard four institutional distances mentioned } \\
\text { above as the cognitive variable, and use two categories of logic } \\
\text { regression model for the regression analysis based on the } \\
\text { investment model of investment enterprises in Laos. This } \\
\text { model is used to evaluate Cox \& Shell and Nagelkerke } \\
\text { coefficient and decision-making coefficient is respectively } \\
0.299 \text { and } 0.399 \text {. The expected accuracy for the four } \\
\text { independent variables introduced into the model is } 74.6 \% \text {, } \\
\text { which is increased by } 20.2 \% \text { than that before the introduction. } \\
\text { This indicates that model estimation is effective. }\end{array}$} \\
\hline
\end{tabular}

TABLE VII ECONOMIC THEORY ASSUMPTION INSPECTION ABOUT THE INFLUENCE ON THE AGRICULTURAL INVESTMENT MODE IN LAOS

\begin{tabular}{llcccccc}
\hline & \multirow{2}{*}{ Institutional distance } & & Standard & & \multicolumn{2}{c}{ Degree of } & \multicolumn{2}{c}{ Significanc } \\
freedom & e & Exp (B) \\
\hline \multirow{3}{*}{ Step I } & Regular & -0.066 & 0.053 & 1.379 & 1 & 0.202 & 0.906 \\
& Nonofficial & -0.167 & 0.086 & 4.247 & 1 & 0.037 & 0.858 \\
& (Constant) & 1.116 & 0.539 & 3.925 & 1 & 0.048 & 3.027 \\
\hline \multirow{3}{*}{ Step II } & Politics & -0.134 & 0.071 & 3.404 & 1 & 0.057 & 0.863 \\
& Economy & 0.111 & 0.104 & 0.978 & 1 & 0.323 & 0.527 \\
& Law & 0.041 & 0.073 & 0.318 & 1 & 1.117 & 1.034 \\
& Culture & -0.359 & 0.157 & 6.018 & 1 & 0.012 & 0.687 \\
& (Constant) & 0.939 & 0.571 & 2.750 & 1 & 0.095 & 2.567 \\
\hline
\end{tabular}

a. Variables input in Step II: Official institutional distance and nonofficial institutional distance; $b$. The dependent variable is the investment mode. 0 and 1 are respectively the independent investment mode and joint stock partnership. $c$. Chi-square value is $9.145, \mathrm{p}=0.01$, and under $5 \%$ of significance level, the equation is obvious.

2. Economic theory assumption inspection on official and nonofficial institutional distance. As can be seen from the result, under $5 \%$ of significance level, nonofficial institutional distance has a more obvious influence than official institutional distance on the investment mode of enterprises in Laos (Table 7). The model result shows that, we think that the major factors influencing the agricultural investment mode selected by Chinese enterprises in Laos should be based on policies, finance, laws and other official system factors, but the fact is just the opposite. These factors are not considered by most enterprise owners and local managers. The core of the influence is generally nonofficial institutional distance factors, such as the institutional distance of culture. This is because China and Laos have many similarities in official systems, with small differences in the cognition of official systems. It is not a major factor influencing the investment mode of enterprises. For these two countries, nonofficial institutional distance between the two countries is far bigger than the official institutional distance. Therefore, the difference in the cognitive 
perception of nonofficial systems, such as the difference in cultural distance will be more obvious. Different cognitive differences can exert a big influence on selecting the mode of investment enterprises. [7] The bigger the distance with nonofficial system is, more enterprises tend to select independent investment mode. Independent investment mode has avoided the internal abrasion and loss incurred by nonofficial system differences in culture, but this may also increase the external abrasion and external cost of enterprises. [8] Since independent investment is inferior to equity cooperation mode in integrating local culture and understanding local nonofficial systems by comparing with stock cooperation mode, more abrasions can be easily incurred when enterprises are interacting with local residents and the government. Therefore, this has increased external cost. [9]

\section{Economic theory assumption inspection on the influence of investment performance}

Assuming that Chinese enterprises think that the bigger the cognition on institutional distance of four dimensions in the target market in Laos is, the better the operational performance of Chinese enterprises in the target market. Obviously, when studying Assumption $\mathrm{H}_{0 * 2}$, the cognition on institutional distance can exert obvious positive influence on the operational performance of enterprises.

Conduct simple linear regression by adopting the cognition on the institutional distance from four dimensions as the independent variable, including the institutional distance of policy, economy and finance, laws and cultural distance. Dependent variable refers to the operational performance of China-invested agricultural enterprises in Laos. According to Table 9 , under $5 \%$ of significance level, the bigger the cognition on the institutional distance of economy and finance is, the better the operational performance of enterprises will be.

TABLE VIII ECONOMIC THEORY ASSUMPTION INSPECTION ABOUT THE INFLUENCE OF INSTITUTIONAL DISTANCE COGNITION ON THE AGRICULTURAL PRODUCTION OPERATIONAL PERFORMANCE OF CHINESE ENTERPRISES IN LAOS

\begin{tabular}{|c|c|c|c|c|c|c|}
\hline \multirow{2}{*}{\multicolumn{2}{|c|}{ Institutional distance }} & \multicolumn{2}{|c|}{ Non-standardized coefficient } & \multirow{2}{*}{$\begin{array}{c}\text { Standard coefficient } \\
\text { Trial version } \\
\end{array}$} & \multirow{2}{*}{ T value } & \multirow{2}{*}{ Significance } \\
\hline & & $\mathrm{B}$ & Standard error & & & \\
\hline \multirow{3}{*}{ Step I } & Official institutional distance & 1045.57 & 28.547 & 0.469 & 3.721 & 0.000 \\
\hline & Nonofficial institutional distance & 15.313 & 31.915 & 0.061 & 0.507 & 0.638 \\
\hline & (Constant) & -1155.05 & 226.471 & & -5.213 & .000 \\
\hline \multirow{6}{*}{ Steps II } & Institutional distance of policy & 7.86 & 26.04 & 0.043 & 0.312 & 0.724 \\
\hline & Institutional distance of economy and finance & 96.000 & 40.002 & 0.417 & 2.210 & 0.020 \\
\hline & Institutional distance of laws & 26.935 & 29.113 & 0.142 & 0.943 & 0.337 \\
\hline & Cultural distance & 14.001 & 26.928 & 0.069 & 0.493 & 0.598 \\
\hline & Psychological distance & -40.123 & 40.22 & -0.149 & -1.106 & 0.320 \\
\hline & (Constant) & -1217.201 & 230.106 & & $-5 . \quad 516$ & .000 \\
\hline
\end{tabular}

In Step I, a. Dependent variable: Average operation over 5 years (profits: RMB ten thousand yuan) b. F=4.346, p=0.002 and under 5\% of significance level, the equation is significant; In Step II, a. Dependent variable: Average operating profits over five years (ten thousand); b. $\mathrm{F}=8.975, \mathrm{p}=0.000$, and under $5 \%$ of significance level, the equation is significant.

As shown in the result of Table 8 , under $5 \%$ of significance level, the perception of official institutional distance can exert obvious influence on business performance. Enterprises think that, the bigger the official institutional distance between China and Laos is, the better the corporate performance will be. The reason is that the official institutional distance between China and Laos is a objective decision. If enterprises hold that official institutional distance is big between the two countries (including political, economic, financial and legal distance), they may think there will be more risks in business procedures. [10] Therefore, in the process of corporate management, enterprises tend to careful operation, and reinforce management, and decrease the cost of operation and management as much as possible. Such enterprises can acquire better operational performance than enterprises with smaller cognitive distance. ${ }^{[1]}$

\section{RESULT AND SUGGESTIONS}

\section{A. Relevant conclusion}

(1)Under the same institutional distance, there are differences in the institutional cognition of enterprises, which will influence the investment mode and operational performance of agricultural enterprises invested by China in Laos. As can be seen from the result of empirical model, the distance between the institutional distance of policy and economy is the institutional distance in form. There is a huge difference in the cognition of nonofficial institutional distance (such as cultural distance). It can influence the enterprises' investment mode and the operational performance.

(2)The obvious influence on the investment performance of enterprises is mainly caused by the official institutional distance. Objectively speaking, it is certain that official institutional distance exists between China and Laos. Once it is held that the official institutional distance of policy, economy and laws, etc. in the two countries is bigger, Chinese enterprises will realize that they will face more uncertainties in the policy, convenience, etc. as well as bigger risks in 
investment and operation, in respect of the agricultural investment in Laos. Therefore, on the basis of conservatism principle, they will tend to careful operation and reinforced management in the process of investment and operation, and improve management efficiency by decreasing investment cost. Enterprise managers with bigger cognition on the institutional distance can obtain better operational performance easily when comparing with enterprises that has general cognition on the institutional distance.

(3)Cultural distance and nonofficial institutional distance are important factors. When considering the institutional distance for selecting the investment mode, enterprises have considered more the differences of nonofficial institutional distances in cultural distance, etc. Since the influence of the nonofficial system on Sino-Laos agricultural investment has exceeded the regular system, enterprises should not only communicate with the home government, but also interact with local government and residents. To decrease interaction with local government and the people, and decrease excessive abrasion cost in the internal management process, enterprises with stronger cultural distance tend to select the mode of individual proprietorship

(4)The institutional distance of economy and finance can exert an obvious influence on investment performance. When enterprises think that the target country and the country are of bigger differences in the economic and financial system, they will be more cautious when selecting business mode and scale, and will often get better business in the lack of fund. Especially when agricultural products are of low price, enterprises are hard to get cash profits, and in case of fund shortage, it is also difficult for them to get financing in China or Laos due to business mode and financial system, etc., Which has caused difficulty in the business operation and even the breakage of fund chain. Therefore, we can see from the agricultural investment made by China in Laos over the past 5 years, the awareness of economic and financial system was stronger and the operational performance of enterprises was also better.

\section{B. Countermeasures and suggestions}

(1)Emphasize on the importance of bilateral coordination of institutional resources. Unilateral government and single entrepreneur cannot supply these institutional resources. It requires the joint negotiation and agreement of bilateral and multilateral governments and entrepreneurs. Besides, the public goods and infrastructures invested abroad should only be supplied by bilateral or multilateral governments. Effectively implement the bilateral and multilateral coordination and negotiation of institutional resources, for instance, docking with bilateral government management system, negotiating financial tax system and establishing practice standard. Our highest priority is to coordinate two institutional distances. Firstly, it is to formulate encouraged or restricted agricultural investment standard between governments of the agricultural investment country and the host country, and make clear the investment bottom line standard for agricultural investment enterprises in the invested country. Secondly, banking institutions of the bilateral government should further make clear and define corresponding financial policies, and provide financial preference policies.
(2)We should admit the existence of cultural difference and decrease the gap as much as possible. We should admit or cognize macro to micro changes of the two countries in institutional distance. It is certain that the macro institutional distance of national level and between countries in policy, economy and finance, legal policies, etc. is critical, but the micro system established, promoted and accumulated by each enterprise in each region is more important. In the field of investment by Chinese enterprises, we must keep fair and just progress, avoid falsely publicizing and deceiving local people, and should decrease the damage to the local social culture and traditional habits as much as possible. When selecting the business mode, we should try to establish an interest community closely related to the local people; when returning to the local people and local communities, we should adopt the mode and method accepted by the local, and avoid arbitrary actions in their subjective desire.

(3)We advocate the two countries to seek common points while reserving differences in institutional distance. This is a new institutional culture, which means that, without core profit conflicts, we should seek for handling common disputes, realize a win-win result in economic profits and community development, rather than political consistency. On the basis of mutual understanding and respect, we allow diversified life choices. We can spend more time waiting in the field that we cannot understand each other and reach consensus.

\section{ACKNOWLEDGMENT}

Fund project: Young and Middle-aged Fund of Yunnan Agricultural University: Study on the Influence of Institutional Distance between China and Southeast Asian Countries on the Agricultural Investment Mode and Performance-taking China and Laos as an Example

The First Author: Xuekun LI (1972-), male, Associate Professor of Yunnan Agricultural University, engaged in studying the management of agricultural economy.

Corresponding Author: Yuqin ZHANG (1974-), female, Associate Professor of Yunnan Agricultural University, engaged in studying agricultural economics.

\section{REFERENCES}

[1] Shengyao TANG. Strategic Selection for Agricultural Cooperation between China and ASEAN [J]. World Agriculture, 2008, (12): 3-6.

[2] Zhigang MA, Qun XIE, and Chen ZHANG. Discussion about the Mode To Reinforce the International Competitiveness of Agricultural Products by Utilizing Regional Resources [J]. World Agriculture, 2011, (03): 9-14.

[3] Weilai XI. Research on Theories and Demonstration Adopted by Laos To Attract Chinese FDI [D]. Jinan: Shandong University, 2011.

[4] Rui LEI. Research on the Influence of Institutional Distance between China and Southeast Asian Countries on the Investment [J]. Inquiry Into Economic Issues, 2017, (05): 21-26

[5] Zhongyuan ZHANG. Institutional Quality of the Host Country, Bilateral Investment Agreement and China Foreign Direct Investment [J]. Southern Economy, 2013, 31 (04): 49-62.

[6] Xinfei HUANG, Yuan SHU, and Yumin XU. Difference between the Institutional Distance and Transnational Incomes $[\mathrm{J}]$. Economic Research, 2013, (09): 20-27

[7] Su CHEN. Influence of Institutional Distance on Cross-border Risk Investment Performance-empirical Test Based on Chinese Market [J]. Research on Financial and Economic Issues, 2017, (07): 5-11 
[8] Yajie YE. Research on the Foreign Direct Investment of Chinese Enterprises from the Perspective of Institutional Distance[J]. Henan Social Sciences, 2017, (06): 44-52

[9] Daying YAN. Research on Institutional Distance, International Experience and the Success or Failure of Chinese Enterprises in Overseas Merger and Acquisition[J]. Nankai Economic Studies, 2011, (10): $22-29$

[10] Huaichao CHEN, and Jianhong FAN. Merger and Acquisition of Chinese Transnational Corporations and the Selection of Green Spaces under Institutional Distance--based on the Perspective of Organizational Legitimacy [J]. Word Economy Studies, 2013,(12): 25-34

[11] Xiaoyun WU, and Huaichao CHEN. Research on the Knowledge Transfer of Transnational Corporations Based on Institutional Distance [J]. Inquiry Into Economic Issues, 2011, (09): 46-53. 